\title{
Complex spectral-acoustic monitoring of the state of fluid-saturated coal-rock mass
}

\author{
Yurii Pylypenko ${ }^{1,}$, Iryna Konstantynova ${ }^{1}$, and Kchichtof Ozet $^{2}$ \\ ${ }^{1}$ Institute of Geotechnical Mechanics named by N. Poljakov of National Academy of Sciences of \\ Ukraine, 49005, Dnipro, Simferopolska Str., 2a, Ukraine \\ ${ }^{2}$ Institute of Innovative Techniques, EMAG, 40-189, Katowice, Leopold Str., 31, Poland
}

\begin{abstract}
Annotation. Subject of the research is the methods for monitoring properties and state of coal-rock massif. This work is an experimental validation of the studied parameters of acoustic emission occurred during destruction of the roadway roof. Elements of the theory of acoustic emission control, research methods, results and experimental studies of the fluid-saturated rock destruction were studied. In this article, methods of studying and interpreting the results of geophysical observations of the process of the roof rock stratification and fall at caving of the undermined rocks at a complex stressed state are presented. Biseds, approaches to solving the problems of managing and controlling the dynamics of changes in the stress-strain state of the undermined fluid-saturated coal-rock massif based on factors of autocorrelation between the seismic-acoustic phenomena occurred over time are described. Experimental grounds are given to the complex control methods with determination of the level of disintegration by the Fourier estimation of the amplitude-frequency and amplitude-time spectra.
\end{abstract}

\section{Introduction}

In the process of coal mining, gas-dynamic phenomena often occur when mechanized complexes moves along the zones of discontinuous dislocations. This is especially true for panels disturbed by the low-amplitude tectonics. This problem is constantly getting worse due to the growing gas content in the mines. The complexity of mining and geological conditions leads to the fact when the modern high-performance equipment used for drivage and winning operations [1] cannot meet requirements of technological safety.

The most important challenge for preventing negative consequences of mining operations is to develop proper methods for assessing dynamics of the rock pressure distribution [2, 3]. Location and parameters of zones of discontinuous dislocations are determined by the method of mine seismic prospecting, and center of the crack formation is determined by the method of seismic acoustics (SA) [2]. These methods are based on complex spectral-acoustic control of the state of the fluid-saturated coal-rock massif and include determination of velocity of elastic waves and their

*Corresponding author: igtm.pilipenko@gmail.com 
attenuation in zones of discontinuous dislocations and estimation of dissipative losses during the transition of the energy of coal seam destruction to the energy of seismic-acoustic emission (SAE) generated by the coal-rock massif. Purpose of this work is to specify parameters of the roof fall by the data of geophysical observations and to assess methane emissions into the atmosphere. In order to achieve this purpose, it is necessary to fulfill the following tasks: to develop a method for detecting location of zones of discontinuous dislocations, determining step of the main and immediate roofs caving and assessing gas emission dynamics during the winning operations.

\section{Methodology}

The complex spectral-acoustic control is based on the study of the state of coal seams saturated with fluid and interaction between elastic waves and a medium, which is characterized by a system of directional cracks filled with moisture or gas. Experiments with the rock samples show that when total pressure increases, the number of cracks decreases, strength of rocks increases, and their permeability decreases [4]. Deviations from these patterns are explained by several reasons, including continuous physical and chemical processes in coals and rocks filled with fluid and gas. This is manifested by time variations of emissions, including at great depths.

Strength of the brittle rocks is well approximated by the modified Coulomb-Mohr condition.

$$
\sigma_{p}=\tau_{c}+f\left(\sigma_{n}-P\right)
$$

where $\tau_{c}$ - rock adhesion, MPa, $f$ - relative coefficient of shear friction, relative units, $\sigma_{n}$ normal voltage, $\mathrm{MPa}, P$ - pressure of the liquid filling the crack, MPa.

When coefficient of friction is small, and stress and pressure of the liquid filled the cracks are equal, then, at greater depths, shear strength will be determined by the cohesion of the rocks, which increases with pressure as the size of the cracks decreases and the elastic modulus increases. With the depth, the fluids reduce the energy of the crack free surface. This hypothesis is used as a basis for studying the rock strength and stress state by parameters of seismic-acoustic pulses [5].

The passage of elastic waves through the gas-saturated medium is characterized by a scalar displacement potential. For the potentials, wave equations are formulated for the radiation conditions, which are solved by the method of Fourier transform for time coordinates with taking into account boundary conditions in the contact area between the gaseous and elastic media [2]. For calculating seismic-acoustic fields in the gas-saturated media when elastic waves are dissipated along the inclusions, the Fourier integrals are used, which describe potentials in elastic medium by the stationary phase method. This makes it possible to analyze potential fields when solving a direct problem of seismic acoustics and select directional patterns of acoustic vibration receiversthe geophones.

Rock-mass stress state is determined by dynamics of destruction registered by the method of seismic-acoustic control. The rock strength is estimated by duration of a single signal and intensity of acoustic emissions.

Since the destruction process is discrete, it is necessary to interpolate the events by the time interval in order to detect abnormal effects in the normal acoustic filed. However, there are some mathematical difficulties.

Shape of the pulse, parameters of which are correlated with the strength and elastic properties of the rocks directly in the rock mass, is shown in Fig. 1. 


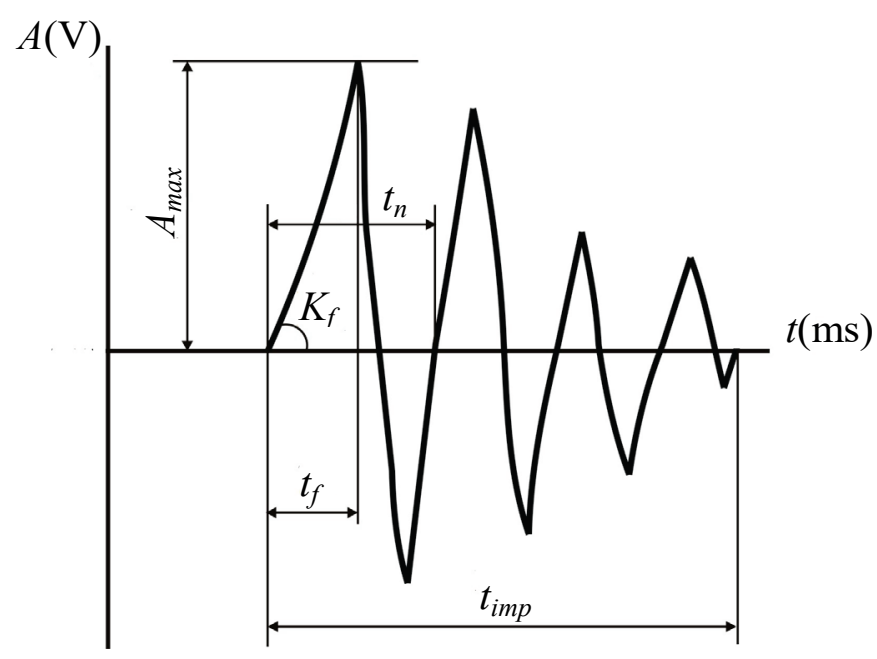

Fig. 1. Information parameters of seismo-acoustic pulses generated during the destruction of rock samples: $A_{\max }$ - the maximum amplitude of the pulse, $\mathrm{V}, t_{\text {imp }}$ - pulse duration, ms, $t_{n}$ - time period of the pulse rise, $\mathrm{ms}, t_{f}-$ pulse front duration, $\mathrm{ms}, K_{f}-$ steepness of the acoustic pulse front, $\mathrm{V} / \mathrm{ms}$.

The results of determination of the centers of crack generation and recorded acoustic signal shape were used for studying the SAE frequency characteristics at various types of the crack formation. Cracks were identified by frequency composition and crack generation range, amplitude, entry time and sign of the first phase.

For effective managing the control process, parameters of acoustic pulse associated with determination of the coal elastic and strength properties were generalized and validated. By this way, intensity of acoustic emission, which accompanies formation of large cracks, is determined. Intensity of the acoustic emission is proportional to the number of connections or the number of cracks in the volume and depends exponentially on energy of discontinuity activation under the constant load and on the average stress values $[4,5]$.

Qualitative and quantitative assessment of crack formation is made by solving the problem of surface restoration by using discrete information specified in the nodes of rectangular lattice. The most universal method is piecewise linear splines [6].

Propagation of seismic-acoustic pulses along the rock mass depends on the environment, its properties and state, that is, it is under the effect of dissipation. Acoustic emission was studied during destruction of coals and rocks at different loading conditions (uniaxial and volumetric compressions).

Experimental seismograms are used for determining semi-range of amplitudes $A_{I}$ and $A_{I-1}$ and time intervals, while initial data for estimating dissipative losses during the destruction and elastic vibration propagation in the fractured medium are calculated by the method [2].

Processing of the experimental results allows choosing an analytical expression for describing force characteristics and establishing dominant influence of the fracturing and moisture or gas saturation. Since the acoustic emission is caused by the growth of cracks, the amplitude-frequency and amplitude-time spectra reflect their relative quantitative characteristics.

As an example, the calculation results for the coefficient of dissipative losses in the fractured rocks are shown in Table 1.

As follows from the Table 1 , minimum loss 0.72 was demonstrated by monolithic sandstones, and maximum losses - by less strong, layered and fractured sandstones. 
Table 1. Dissipative losses of acoustic emission in disturbed rocks.

\begin{tabular}{|c|c|c|c|c|c|c|}
\hline \multirow{3}{*}{ Rocks } & \multirow[b]{2}{*}{$\begin{array}{c}\text { Semi } \\
\text { range } \\
A_{i}\end{array}$} & \multirow[b]{2}{*}{$\begin{array}{c}\text { Amount of } \\
\text { semi-ranges } \\
x_{i}=A_{i-1}+A_{i}\end{array}$} & \multirow[b]{2}{*}{$\begin{array}{l}\text { Amount of } \\
\text { semi-ranges } \\
y_{i}=A_{i-1}-A_{i}\end{array}$} & \multicolumn{2}{|c|}{ Logarithm } & \multirow{3}{*}{$\begin{array}{c}\text { Dissipative } \\
\text { loss } \\
\text { coefficient, } \\
\text { in relative } \\
\text { units }\end{array}$} \\
\hline & & & & \multirow{2}{*}{$\begin{array}{l}\text { amounts } \\
\text { semi- } \\
\text { ranges } \\
\lg x_{i}\end{array}$} & \multirow{2}{*}{$\begin{array}{l}\text { amounts } \\
\text { semi- } \\
\text { ranges } \\
\lg y_{i}\end{array}$} & \\
\hline & \multicolumn{3}{|c|}{$\mathrm{cm}$} & & & \\
\hline \multirow{3}{*}{ sandstone } & 10.00 & - & - & - & - & \multirow{3}{*}{0.72} \\
\hline & 6.84 & 16.84 & 3.16 & 1.22 & 0.50 & \\
\hline & 5.05 & 11.89 & 1.79 & 1.07 & 0.25 & \\
\hline \multirow{3}{*}{ siltstone } & 3.92 & 8.97 & 1.13 & 0.95 & 0.05 & \multirow{3}{*}{0.43} \\
\hline & 3.14 & 7.06 & 0.78 & 0.84 & -0.10 & \\
\hline & 2.58 & 5.72 & 0.56 & 0.75 & -0.25 & \\
\hline \multirow{3}{*}{ argillite } & 2.17 & 4.75 & 0.41 & 0.67 & -0.38 & \multirow{3}{*}{0.32} \\
\hline & 1.85 & 4.02 & 0.32 & 0.60 & -0.49 & \\
\hline & 1.60 & 3.45 & 0.25 & 0.53 & -0.60 & \\
\hline
\end{tabular}

Rocks in the sedimentary bed are considered as a 3-component medium (coal, water, gas), which is in thermodynamic equilibrium. Mining operations disturb this state and provoke strengthening of existing and emergence of new mechanisms of the acoustic vibration generation. Moisture or gas saturation not only affects acoustic activity of the solid part of the strata, but also can generate acoustic vibrations during the gas draining or when filtration flow becomes unstable featuring the pulsed velocity and pressure [7]. This is caused by manifestations of effective stresses, especially at roof caving leading to the emergencies.

All of the methods used for rock-mass stimulation are associated either with transferring coal seams into the mobile state, or with the use of technologies, which reduce outburst hazard of the seams. The choice of the method for impacting the coal seam depends on the mining and geological conditions and the presence of significant content of gas.

Zones with tectonic disturbance were studied in mine by the intrinsically safe digital seismic station PASSAT-M. This equipment consists of separate functional units connected with each other by the fiber-optic cable. Control, monitoring and setting of modes is carried out through the terminal.

Works in the mine conditions were carried out on the $m_{3}$ formation in the seismicprospecting profiles. The latter are a network of the observation stations in the form of anchors, on the shanks of which either the receiving modules or the plugs, which the hammer strikes, are screwed on. Distance between the observation points was $15 \mathrm{~m}$. The work was performed in the mode of seismic profiling of the coal column (elastic waves were excited in the air roadway of the longwall and were receipted in the belt road). In this case, the wave power was excited by the surface source with a wide spectral composition. As a result of the mine studies, velocities of elastic waves in zone with disturbance, monolithic rocks and coal seam were obtained. These data are necessary for determining centers of crack formation in case of the roof fall. Hodographs are necessary for determining boundaries of zones with tectonic disturbance and calculating dissipative losses by the data of the mine observations.

Scheme of the observations and fragment of the time field registered by the system of seismic receivers located along the length of the belt road are shown in Fig. 2.

Seismic events were registered by the equipment and instruments of digital multichannel seismic monitoring ARES-5/E. For this purpose, geophones were installed in the mine roadways, and their coordinates were fixed. By knowing the distance between the 
points of acoustic signal reception, velocity of elastic waves and times of their arrival, it is possible to determine spatial location of the centers of crack formation. When rock falls, acoustic effects are created, which are estimated by the energy of acoustic emission, in joules. At the same time, the rock strength is determined, which is correlated with the mining-technical parameters of the roof, and, in accordance with the provision of the Don UGI instructions in terms of classification of roofs by their manageability and collapsibility, the fall step is calculated.

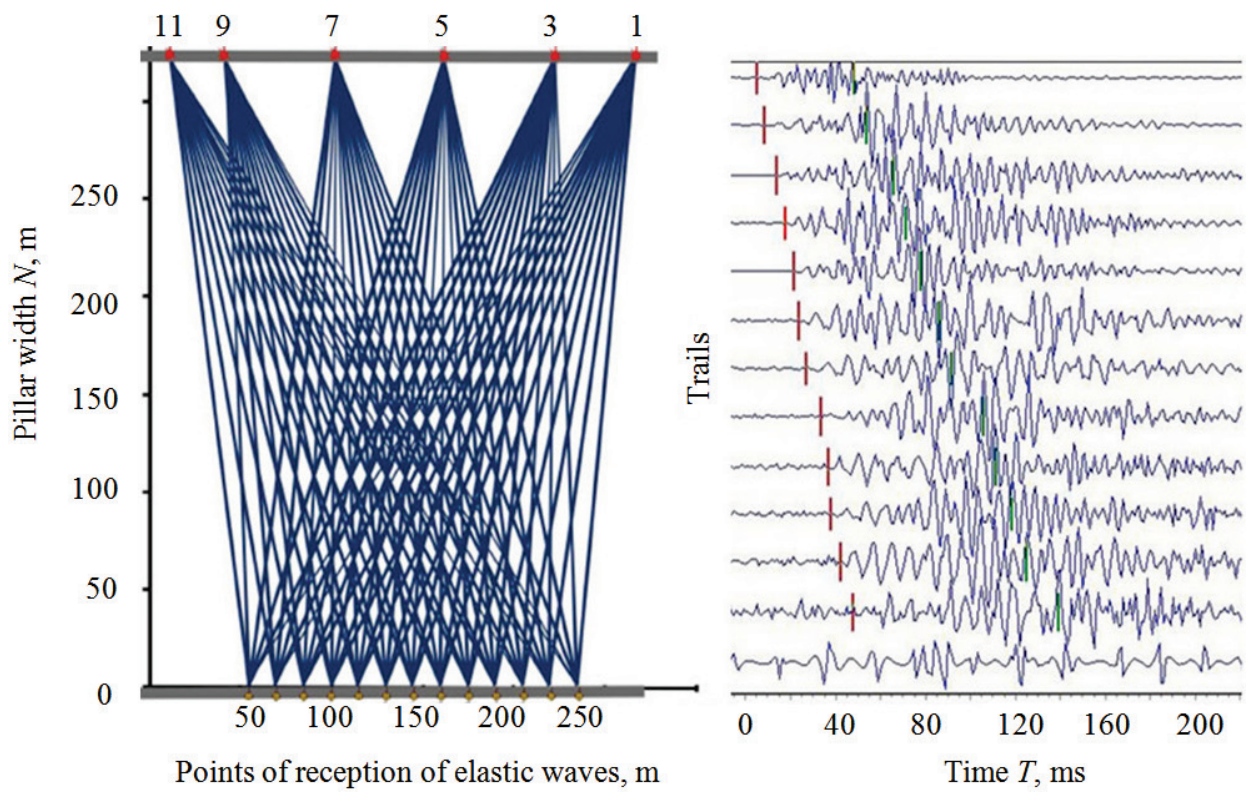

Fig. 2. Observation scheme and time field of the waves passing in zone with low-amplitude disturbance (overthrust) along the 18th western longwall of the $m_{3}$ formation.

Stress state of the face area in the coal seam is estimated by the ARAMIS M/E station used for detecting seismic event by the standard method [8-10] and by the method of borehole drilling and with the help of multicomponent deformometers [6, 7].

Gas emissions are determined experimentally through the boreholes, which are drilled from the belt road. All the boreholes are drilled to the rise with lifting angles from $15^{\circ}$ to $60^{\circ}$ and with different lengths and directions: towards unloaded rock mass and towards the working seam. The borehole is drilled from the coal seam, with passing through the whole thickness and further to the satellite layers. The boreholes are sealed, equipped with valves, pressure gauges for measuring gas pressure (MT) and self-recording pressure gauges (MTS 712-KI MGGA). Rate of gas emissions is measured by the method of Mac NII by using the device $2 \mathrm{G} 2 \mathrm{M}$ A.

\section{Results and discussion}

The necessity to determine zone with low-amplitude tectonic disturbances is associated with the need for a comprehensive application of the method of mine seismic exploration, since the area is represented by the disturbed rocks. This is also explained by the need to determine velocity of elastic waves in the coal seam and side rocks in order to detect centers of the crack formation at the roof destruction. The average velocities of longitudinal and transverse waves outside the zone of discontinuous dislocations are shown in Table 2. 
Table 2. Parameters of elastic characteristics of the coal seam along the width of the panel.

\begin{tabular}{|c|c|c|c|c|}
\hline Stakes & $\begin{array}{c}\text { Distance by the width } \\
\text { of the panel } H, \mathrm{~m}\end{array}$ & $\begin{array}{c}\text { Velocity of the } \\
\text { longitudinal } \\
\text { wave } V_{p}, \mathrm{~km} / \mathrm{s}\end{array}$ & $\begin{array}{c}\text { Velocity of } \\
\text { the transverse } \\
\text { wave } V_{s}, \\
\mathrm{~km} / \mathrm{s}\end{array}$ & $\begin{array}{c}\text { Attenuation } \\
\text { coefficient }\end{array}$ \\
\hline 1 & 15 & 3.57 & 1.72 & 0.35 \\
\hline 3 & 45 & 3.80 & 1.79 & 0.36 \\
\hline 5 & 75 & 3.99 & 1.82 & 0.37 \\
\hline 7 & 105 & 3.48 & 1.72 & 0.34 \\
\hline 9 & 135 & 3.89 & 1.83 & 0.36 \\
\hline 11 & 165 & 3.61 & 1.81 & 0.33 \\
\hline 13 & 195 & 3.64 & 1.74 & 0.35 \\
\hline 15 & 225 & 3.68 & 1.70 & 0.36 \\
\hline 17 & 255 & 3.27 & 1.55 & 0.36 \\
\hline
\end{tabular}

The presented results describe general acoustic characteristics of the geological environment and its state. Contour of the disturbed zone is determined by maximum abnormal changes of these characteristics. The roof state was studied during the winning operations by the amplitude and frequency characteristics. as well as by maximum amplitude of the envelope, maximum parameters of the amplitude spectrum, and coefficient of wave absorption in the roof and floor of the coal seam. The dependences between elastic wave propagation in the form of time hodographs (Fig. 3) and characteristics of the channel waves (Fig. 4) are constructed in accordance with the seismic data.

The hodographs are needed for determining boundaries of zones with tectonic disturbance and calculating dissipative losses on the basis of the results of the mine observations. As an example, the dependences of velocity on frequency of the channel waves for the disturbance of the overthrust type are shown in Fig. 4; these dependences were calculated by the method [10].

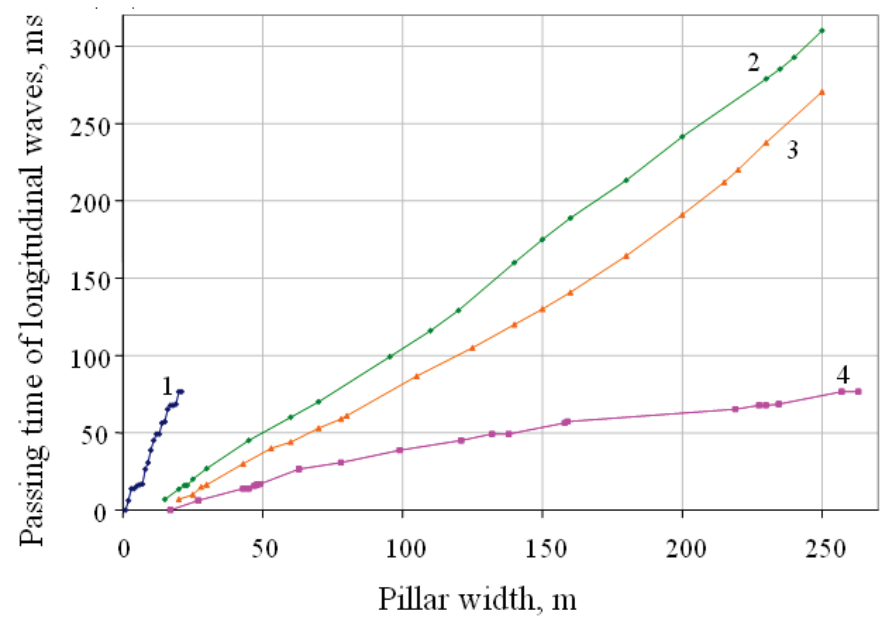

Fig. 3. Traveltime of passing waves in the zone of discontinuous dislocation: 1 - in the zone of influence of mine workings, 2, 3- in the zone of the monolithic state of the coal seam, 3, 4-in the zone of tectonic disturbance. 


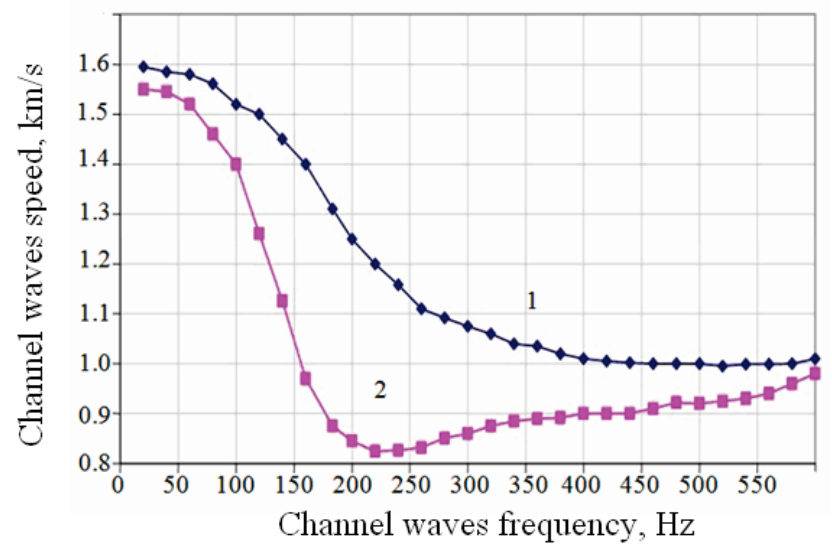

Fig. 4. Propagation of channel waves (V) in zone of discontinuous dislocation: 1 - calculated dependence, 2 - experimental dependence.

Analysis of the values of the coefficients of kinematic, dynamic and spectral parameters in the area under the research allowed establishing route of disturbance, which extended in the area of the following stakes: air roadway 380-400 and belt road 410-420. Propagation of elastic waves depends on the factual loads and degree of the rock and coal heterogeneity and fracturing.

In practice, the developed methodological provisions were implemented in the mine conditions while evaluating the state of the roof of the gas-bearing coal seam $\mathrm{m}_{3}\left(\mathrm{~m}_{3}\right.$ is the index of the coal seam) in zone of tectonic disturbances of the A. F. Zasyadko Mine. Propagation of elastic waves depends on the factual loads and degree of the rock heterogeneity and fracturing, so it is necessary to locate the acoustic vibration receivers in such a way as to minimize the error in determining the wave velocity. Scheme of the polygon with location of geophones $1,2,3,4,5$ relative to the 18th western longwall are shown in Fig. 5.

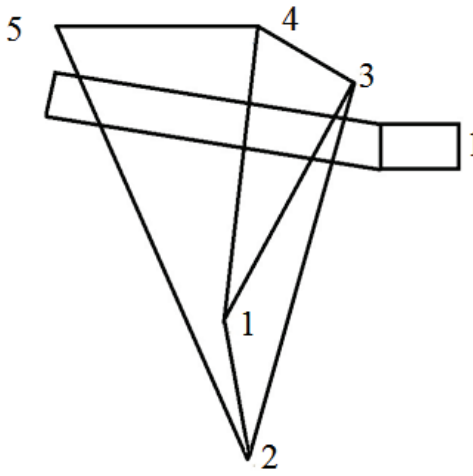

18-th western wall

Fig.5. Polygon of geophone locations for calculating the difference in time interval arrival.

Among the work processes, the predominant influence on the SAE parameters exerts caving of the main and immediate roofs. Thickness of the loose rocks and the step of the fall depend on the rate of the face advancing.

Mine studies of the SAE allowed determining frequency of the roof destruction and establishing physical and mechanical properties of the roof. As a result of experimental studies, the presence of a close correlation between two sets of data: the values of the CA pulse duration and the strength of $N$ rocks. The equations are shown in Table 3. 
Table 3. Equations of regression for rock strength and duration of the SA pulse.

\begin{tabular}{|c|c|c|}
\hline Geomaterial under the study & Regression equation & Correlation coefficient \\
\hline Argillite & $N=0.006{t_{i m p}}^{-1.2}$ & 0.59 \\
\hline Sandstone & $N=0.302{t_{i m p}}^{-1.5}$ & 0.73 \\
\hline Siltstone & $N=0.004 t_{i m p}{ }^{-4.1}$ & 0.62 \\
\hline
\end{tabular}

While studying loads on the face area of the coal seam and mechanized support by the SAE method [7], three periods of manifestation of the main roof caving were identified by the index of spectral concentration. Each of the periods is characterized by certain parameters of the SAE activity. According to the results shown in Table 4, main roof falls in three stages. The first one is characterized by a high rate of crack development due to the successive displacement of the roof, which results in unloading of the undermined massive. The second stage is fall of the main roof. Most indexes indicate an increased intensity of the SAE, and, as a result, increased stress before the roof caving. The third stage is total caving of the main roof. The increased spectral concentration and frequency range indicate the increased stress of the main roof, up to its fall.

Table 4. The results of the evaluation of the SAE indexes at caving of the main and immediate roofs.

\begin{tabular}{|c|c|c|c|c|c|c|c|}
\hline \multirow[b]{2}{*}{$\begin{array}{c}\text { Technological } \\
\text { process }\end{array}$} & \multirow[b]{2}{*}{$\begin{array}{c}\text { Roof } \\
\text { rock } \\
\text { density } \\
t / \mathrm{m}^{3}\end{array}$} & \multirow[b]{2}{*}{$\begin{array}{c}\text { Compressive } \\
\text { strength, } \\
\mathrm{MPa}\end{array}$} & \multirow[b]{2}{*}{$\begin{array}{l}\text { Longitudinal } \\
\text { wave speed, } \\
\mathrm{km} / \mathrm{s}\end{array}$} & \multicolumn{4}{|c|}{ SAE indexes } \\
\hline & & & & $\begin{array}{c}\text { Pulse } \\
\text { duration, } \\
\text { ms }\end{array}$ & $\begin{array}{l}\text { Intensity, } \\
\text { imp/day }\end{array}$ & $\begin{array}{c}\text { Frequency } \\
\text { range, } \\
\mathrm{Hz}\end{array}$ & $\begin{array}{c}\text { Index of } \\
\text { spectral } \\
\text { concentr } \\
\text { ation }\end{array}$ \\
\hline $\begin{array}{l}\text { Caving of } \\
\text { direct roof }\end{array}$ & 2.4 & 48 & 2.50 & $49-57$ & $17-21$ & 150 & 0.32 \\
\hline $\begin{array}{l}\text { Caving of } \\
\text { the main } \\
\text { roof }\end{array}$ & 2.5 & 48 & 2.80 & $30-35$ & $32-39$ & $>350$ & 0.64 \\
\hline $\begin{array}{c}\text { Total } \\
\text { caving of } \\
\text { the main } \\
\text { roof }\end{array}$ & 2.5 & 48 & 2.67 & $22-24$ & $47-62$ & $350-490$ & 0.72 \\
\hline
\end{tabular}

In case of any delay, intensity of gas emissions increases. Period after secondary caving of the main roof is characterized by the absence of overhangs in the goaf, which leads to significantly more intensive overall phone of acoustic activity. In Fig. 6, a fragment of the roof falls in zone of discontinuous dislocation is shown in the form of a spline surface of the SAE energy. The spline surface was constructed on the basis of the recorded more than 370 acoustic events registered and processed automatically by the ARES-5/E digital monitoring station.

The most intensive growth of SAE is observed at the main roof fall. Comparison of the calculated data in terms of frequency of the roof fall with gas emission shows the correlation dependence, though coefficient of correlation is insignificant. This fact is explained by many factors, which are difficult to take into account, and which include: unsteady rate of the face advance; differences in the properties and state of the host rocks; presence of zones with high rock pressure. Rate of the face advancing features a particularly strong effect on the gas emissions, since it depends on intensity of manifestations of the stress-strain state of the under-mined rock mass. The study of dependence between the rock pressure manifestations and rate of the face advance shows the degree of influence of the rock-mass physical and mechanical properties, especially of deformation, on the gas draining performance. During the formation of the reference 
pressure under conditions of different rates of the face advance, significant changes occur depending on the nature of the deformation development.

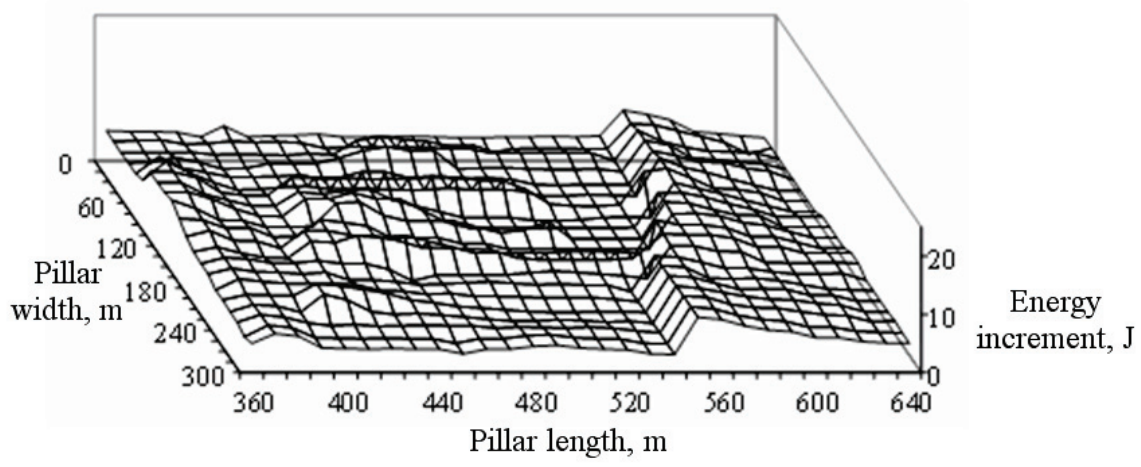

Fig.6. Spline surface of SAE energy at roof caving in the disturbed zone of the 18th western longwall of the $m_{3}$ formation.

During the formation mining, starting from the set-up entry and till the first caving of immediate roof, which means the beginning of rock active stratification, stresses concentrated in zone of reference pressure leads to the fall of the main roof. During this period, gas emissions in the gas drainage boreholes increase by up to $20 \%$, according to measurements.

With the higher rate of the face drivage, maximum stress concentration in the roof of the coal seam is shifted towards the goaf, and the SAEs become more intensive. Results of the study of the rocks loading and dynamics of the SAE changes are shown in Table 5.

Table 5. Dynamics of the SAE changes depending on the rate of the winning operations advancing and load on the face area of the coal seam.

\begin{tabular}{|c|c|c|c|c|c|c|}
\hline $\begin{array}{c}\text { Thickness of } \\
\text { the loose } \\
\text { roof, } \\
\mathrm{m}\end{array}$ & $\begin{array}{c}\text { Density of } \\
\text { the roof } \\
\text { rocks, } \\
\mathrm{t} / \mathrm{m}^{3}\end{array}$ & $\begin{array}{c}\text { Load on the } \\
\text { face area } \\
\text { of the coal } \\
\mathrm{seam}, \\
\mathrm{t} / \mathrm{m}^{2}\end{array}$ & $\begin{array}{c}\text { Loading } \\
\text { rate } \\
\text { ton } / \mathrm{m}^{2} \\
\text { per day }\end{array}$ & $\begin{array}{c}\text { The SAE } \\
\text { pulse } \\
\text { duration, } \\
\text { min }\end{array}$ & $\begin{array}{c}\text { Fulse } \\
\text { putensity/day }\end{array}$ & $\begin{array}{c}\text { frequency } \\
\text { range, } \\
\mathrm{Hz}\end{array}$ \\
\hline $5-7$ & 2.4 & $11-17$ & 0.42 & 42 & 18 & $50-100$ \\
\hline $3-4$ & 2.4 & $6.8-7.3$ & 0.99 & 30 & 23 & $200-280$ \\
\hline $1-2$ & 2.4 & $3.1-4.9$ & 1.78 & 24 & 42 & $>800$ \\
\hline
\end{tabular}

These data show that rate of the rock loading constantly increases with increase of the rate of face drivage.

It is characteristic that when rate of the face advancing is less than $4 \mathrm{~m} / \mathrm{day}$, main roof, by its total thickness, abruptly falls and loses any conjunction with the rock mass bedded ahead. It is explained by the fact that in this case, the grown stresses exceed elastic limits of the rocks in comparison with increments of their deformations.

In case of smooth subsidence of supported roof in the goaf, and if rate of face drivage is more than $5 \mathrm{~m} /$ day, degree of the stress concentration decreases. In case of stops or removal of the powered support, load on the coal seam increases.

In the course of the formation mining, starting from the set-up entry and till the first caving of immediate roof, which means the beginning of active stratification of rocks, stresses concentrated in zone of reference pressure increase and lead to the main roof caving.

Measurement of gas emissions in the gas-drainage borehole shows that during this period they increase by up to $30 \%$. According to the deep bench marks in the air roadways, 
in case of different rates of the face advancing, significant changes are observed, which are associated with the nature of the roof rock deformation development [11].

Based on the results of registration of seismic-acoustic emission, functional relationship between the main and immediate roofs and mining characteristics of the rock mass was specified. These characteristics include the following: step of the roof fall $L, \mathrm{~m}$; thickness of the fallen roof layer $K, \mathrm{~m}$; rock strength $N$; thickness of the main and immediate roofs, $G \mathrm{~m}$; thickness of lower layer of the main $\operatorname{roof} P, \mathrm{~m}$; thickness of active direct roof $m, \mathrm{~m}$; index of the roof structural heterogeneity $h_{p}$; strata dip angle, $a$, deg.

The results of processing of technological parameters determined by the seismicacoustic observations and mining indicators are shown in Table 6. The processing was performed by the Don UGI method. Based on these results, steps of the roof falls during the winning operations were determined.

Table 6. Steps of the roof fall during the winning operations.

\begin{tabular}{|c|c|c|c|}
\hline \multirow[b]{2}{*}{$\begin{array}{l}\text { Technological } \\
\text { parameter }\end{array}$} & \multirow[b]{2}{*}{$\begin{array}{l}\text { The equation for determining } \\
\text { step of the roof fall, } \mathrm{m}\end{array}$} & \multicolumn{2}{|c|}{ Border conditions } \\
\hline & & $\begin{array}{c}\text { Dip } \\
\text { angle } \\
\alpha, \text { deg. }\end{array}$ & $\begin{array}{c}\text { Thickness } \\
\text { of the } \\
\text { strata, } \\
\text { m }\end{array}$ \\
\hline $\begin{array}{l}\text { Step of the main roof } \\
\text { fall: primary } L_{1}, \mathrm{~m}\end{array}$ & $\begin{array}{l}L_{1}=32(1+\sin \alpha) K+ \\
+9.3 G(1+\sin \alpha) e^{-0.7 \frac{h_{p}}{N}}\end{array}$ & $>12$ & $>10$ \\
\hline next $L_{2}, \mathrm{~m}$ & $\begin{array}{l}L_{2}=1.41 P+0.47 G+ \\
+0.15 m-5.2\end{array}$ & $>10$ & 18 \\
\hline $\begin{array}{l}\text { Step of the immediate } \\
\text { roof fall: primary } L_{3}, \mathrm{~m}\end{array}$ & $\begin{array}{l}L_{3}=32(1+\sin \alpha) K+ \\
+8.7 G(1+\sin \alpha) e^{-0.7 \frac{h_{p}}{N}}\end{array}$ & $>10$ & 15 \\
\hline next $L_{4}, \mathrm{~m}$ & $L_{4}=8.7 G(1+\sin \alpha) e^{-0.7 \frac{h_{p}}{N}}$ & $>8$ & $>10$ \\
\hline $\begin{array}{l}\text { Step of the main roof } \\
\text { fall in zone of } \\
\text { discontinuous } \\
\text { dislocations } L_{5}, \mathrm{~m}\end{array}$ & $L_{5}=5.2 G(1+\sin \alpha) e^{-0.7 \frac{h_{p}}{N}}$ & 7 & 6 \\
\hline
\end{tabular}

Thus, with taking into account an important role of the rock stratification in formation of gas balance in the mining district and regularities of formation of stratification cavities as reservoirs of and routes for gas flowing, a method was developed for quantifying strength of the roof rocks directly in the massive and their CA parameters depending on dynamics of the roof caving. Parameters of the roof caving and the caving stratifications formed during the development of tensile stresses were studied and obtained as a result of the CA registration of fracturing centers and drilling of gas-drainage boreholes.

\section{Conclusions}

So, specific features of the roof stratification during the face advancing and at caving of the main and immediate roofs were researched by the complex spectral-acoustic methods used for studying properties and state of the fluid-saturated coal-rock mass in zones of discontinuous dislocations, and, as a result, the following regularities are established: 
- relationship between duration of acoustic pulses and rocks strength directly in the massive is established; high accuracy of the rock mass stress-strain state estimations made on the basis of the set of seismic and acoustic characteristics allows using the piecewise linear approximation principle. To this end, the total range of possible changes in the informative parameter values is divided into several intervals, and dependencies are approximated by the linear segments within these intervals. Complex form of the nonlinearity taken into account by the low-power polynomials significantly improves stability of the inverse problem solutions used for controlling the process of crack and stress formation, which lead to the roof falls;

- relationship between mining and technical parameters and step of the roof falls in and outside zones of tectonic disturbances are established. The proposed model of acoustic emission effects based on the phenomenon of existing cracks growing at increasing pressure on the boundaries between the structural elements, allows, with the help of the SAE method, not only to identify location of the emission source, but also to evaluate characteristics of the cracks and fluid saturation in the environment. In order to improve reliability of coal seam stress state evaluation in accordance with the shift of the SAE maximum spectral density, it is necessary to consider mining and geological conditions and totality of physical and mechanical properties;

- rate of the face line advancing affects the parameters of geomechanical processes. Step of the main and immediate roof caving determines parameters of the cavity stratification, and, thereby, determines dynamic pattern of methane emission;

- intensification of crack formation at stratification of immediate and main roofs leads to activation of the SAE. Areas with high level of the roof fracturing are determined by criterion of the ratio between the most stable layers of the host rocks and their thickness;

- specific features of the roof deformation and destruction in the $\mathrm{m}_{3}$ coal seam were specified by results of the SA control, and parameters of stratification were determined by mechanical methods and seismic data at different rates of the face advancing.

The established regularities of gas-dynamic and geomechanical processes occurrred in the coal-bearing thickness under the influence of the face drivage deepen the understanding of conditions, under which gas emission sources are formed due to the stratification of the softer rocks, formation of vertical cracks and changes of the gas condition.

\section{References}

1. O. Voloshyn, O. Riabtsev. Some important aspects of rock mechanics and geomechanics. E3S Web of Conferences, International Conference Essays of Mining Science and Practice, 109 (2019). https://doi.org/10.1051/e3sconf/201910900114

2. Bulat, O.F., Skypochka, S.I., Palamarchuk, T.A. (2009). Metodicheskiye rekomendatsiyi po geofizicheskomu kontrolu i diagnostike geomehanicheskogo sostoyaniya podzemnyh goetehnicheskyh sistem ugolnyh shaht. Donetsk-Dnepropetrovsk: VIK

3. Xu, T., Tang, C.A., Yang, T.H. and others (2006). Numerical investigation of coal and gas outbursts in underground collieries, International Journal of Rock Mechanics \& Mining Sciences, (4), 905-919

4. Bulat, O.F., Pylypenko, Y.N. (2012). Destruction of fluid-saturated geomaterial with a disturbed structure under compression. Geotechnical Mechanics, (109), 4-16

5. Bulat, O.F., Pylypenko, Y.N. (2013). The destruction of fluid-saturated geomaterial in compression. Geologist of Ukraine, 3 (43). 116-123

6. Vynogradov, V.V. (1989). Geomehanika upravleniya sostoyaniyem massiva vblizi gornykh vyrabotok. Kyiv: Naukova dumka

7. Nikolaevskiy, V.N. (1996). Geomehanika i fluidodinamika. Moskva: Nedra 
8. Bulat, O.F., Skypochka, S.I., Pylypenko, Y.N., Dyakun, R.A. (2016). Scientific and methodical basis for spectral-acoustic state control of fluid-saturated coal massif. Geotechnical Mechanics, (114), 3-15

9. Kurlenya, M.V., Serdukov, A.S., Serdukov, S.V., Cheverda, V.A. (2010). Localization of methane accumulation centers in coal seam by seismic method, FTPRPI, (6), 37-47

10. Antsiferov, V.A. (2003). Teoriya i praktika shahtnoy seismorazvedky. Donetsk: Alan

11. Pilipenko Y. N., Pimonenko D. N. (2015) Influence of the type of deformations on the gas content of workings. Problems of safety and efficiency of development of georesources in modern conditions, (1), 399-405 